\title{
De la nostalgia a la invención: Seva. Invasión de Estados Unidos a Puerto Rico
}

\author{
Ximena BERECOCHEA \\ Universidad de Toronto
}

\begin{abstract}
En el ensayo titulado "De la nostalgia a la invención: Seva", se aborda Seva. Historia de la primera invasión norteamericana de la isla de Puerto Rico ocurrida en mayo de 1898, del autor puertorriqueño Luis López Nieves, desde dos perspectivas. La primera se relaciona con el impulso nostálgico que la hace posible, y la segunda con la forma en la que el autor refuerza el contenido, que al parecer funciona como un paliativo a su añoranza. La respuesta del público, se explica, muestra la continuación del sentimiento nostálgico del autor en los lectores. Ciertamente, el efecto de la primera publicación fue definido por la historia común entre autor y lector. Sin embargo, se hace una exposición crítica de los distintos modos de significar que el autor utilizó para configurar el carácter verdadero de su propio y compartido mundo idílico.
\end{abstract}

PALABRAS ClaVE: Seva / Ceiba, Luis López Nieves, colonialismo puertorriqueño, puertorriqueño dócil, heroísmo puertorriqueño.

This essay studies Seva. Historia de la primera invasión norteamericana de la isla de Puerto Rico ocurrida en mayo de 1898 written by Puerto Rican author Luis López Nieves, from two perspectives. The first one is related to the nostalgic impulse that drives the novel, and the second one deals with the way in which the author reinforces the subject matter as palliative to his grief. The readers' reaction is explained as the continuation of the nostalgic impulse of the author. Certainly, the response to this first edition was defined by the shared history of author and readers; nevertheless, in this essay the importance of the different ways of signification that López Nieves used, are emphasized as an important instrument of the truthfulness which characterized this idyllic history.

KEY WORDS: Seva / Ceiba, Luis López Nieves, Puerto Rican colonialism, docile Puerto Rican, Puerto Rican heroism.

Como diría Harold Bloom, la condición poética siempre señala a un mundo idílico que se ha perdido. El canto de John Milton en el Paradise Lost es el canto del ángel-poeta que se reconoce caído. ${ }^{1}$ Esta constante la encontramos desde el relato del Génesis has-

\footnotetext{
${ }^{1}$ En La angustia de las influencias, Harold Bloom habla sobre la revelación entre el Paradise Lost
} 
ta la actualidad. Imaginamos un lugar mejor que el nuestro al cual pertenecimos y en el cual tuvimos un lugar privilegiado; la memoria entonces opera como celebración del pasado, aunque también como mecanismo de añoranza o de tristeza, ya que ese mundo no regresará. Si cualquier tiempo pasado / fue mejor, ${ }^{2}$ el poeta produce universos en los que pretende recrear para el presente espacios que no volverán a suceder jamás: "De toda la memoria, sólo vale / el don preclaro de evocar los sueños". ${ }^{3}$ Poco importa si estos universos han existido algún día. El poeta vive en la intuición de su existencia y esa certeza lo mueve y empuja hacia la palabra y la creación. Para nosotros, lectores, lo que importa es aquello que nos resuena en lo profundo, contándonos del despojo que de alguna manera también experimentamos: la pérdida de nuestra madre, de nuestra casa, nuestra primera partida hacia lo desconocido, la historia que no existió o la aventura de nuestra propia vida.

En uno de los últimos apartados que se anexan al cuento Seva. Historia de la primera invasión norteamericana de la isla de Puerto Rico ocurrida en mayo de $1898,{ }^{4}$ leemos sobre el autor: "Durante una de sus largas noches de estudios doctorales Luis López Nieves sintió de pronto una gran tristeza... de golpe comprendió cuál era la causa de su nostalgia: echaba de menos una epopeya puertorriqueña" (84-85). López Nieves como el ángel-poeta de Milton vuelve la mirada atrás, pero a diferencia de éste, añora lo que no tuvo, y a falta de tenerlo, lo inventa.

En este ensayo se abordará Seva desde dos perspectivas. La primera se relaciona con el impulso nostálgico que la hace posible, y la segunda con la forma en la que el autor refuerza el contenido que, como se verá, funciona como paliativo a su añoranza. Para hablar de la nostalgia y la invención de López Nieves en Seva se presentará un breve esbozo histórico que permita contextualizar la obra y, asimismo, se expondrán algunas ideas que René Marqués presenta en su libro El puertorriqueño dócil, en el que dibuja el perfil del habitante de la isla.

Ya presentadas las bases que definen o se contrapuntean con Seva, se tratará de explicar el sentido de este relato a partir de algunas ideas sobre la nostalgia y se discutirá la recepción que tuvo Seva tras su primera publicación en el periódico Claridad en 1983. La respuesta del público, como se verá, muestra la continuación del sentimiento nostálgico del autor en los lectores. Ciertamente, el efecto de la primera publicación fue definido por la historia común entre autor y lector. Sin embargo, se discutirán también los distintos modos de significar que el autor utilizó para configurar el carácter verdadero de su propio y compartido mundo idílico. A través de una reflexión en torno a la documentación que acompaña la historia narrada, se analizará la manera en la que ésta apoya la falsa veracidad.

de John Milton y cómo William Blake, en su poema dedicado a Milton, le da esta dimensión de ángel caído al personaje de Lucifer.

${ }^{2}$ Jorge Manrique, Coplas por la muerte de su padre el maestre de Santiago don Rodrigo Manrique I (11-12).

\footnotetext{
${ }^{3}$ Antonio Machado, "Renacimiento", LXXXIX (5-6).

${ }^{4}$ De ahora en adelante me referiré a la obra únicamente como Seva.
} 


\section{Historia y reescritura de la historia}

Como es sabido, Puerto Rico fue una de las dos últimas colonias del Imperio español en América Latina; sin embargo, esto no significó la ausencia de un ímpetu independentista. Hubo algunos movimientos revolucionarios que lo muestran, como el bien conocido Grito de Lares en 1868, que fue controlado por los españoles. Al respecto, Antonio Quiñones Calderón expone que hay quienes atribuyen el fracaso de este episodio a la apatía puertorriqueña, mientras que otras visiones más optimistas señalan, por ejemplo, que gracias a éste, España permitió que Puerto Rico organizara los primeros partidos políticos (35). Los diferentes puntos de vista ante un mismo evento muestran que la visión del historiador es definida por un universo individual, a partir del cual comprende e interpreta.

A través de lo que se ha escrito de la historia de Puerto Rico, sabemos que más adelante el destino de esta isla caribeña sería definido por los acuerdos que se negocian entre España y Estados Unidos. Tras la Guerra hispanoamericana, España pide a Estados Unidos iniciar los pasos necesarios para celebrar un armisticio de paz. El presidente estadounidense pone como condición la cesión de Puerto Rico y de las otras islas del Caribe que aún estaban bajo la soberanía española. Más adelante, las tropas estadounidenses invaden el territorio puertorriqueño. En el texto de Quiñones Calderón leemos: "el día 25 de julio, las tropas norteamericanas llegan a la costa meridional de Puerto Rico, al mando del general Nelson A. Miles, e inmediatamente inician su desembarco por el puerto de Guánica" (65). El mismo autor escribe que las tropas fueron recibidas por los puertorriqueños con entusiasmo, además de que numerosos individuos les brindaron ayuda a los recién llegados en las operaciones que realizaban. Unos meses más tarde se firma el Tratado de París y en abril del año siguiente España cede Puerto Rico a Estados Unidos.

En Tropics of Discourse, Hayden White escribe que los teóricos de la historiografía comúnmente coinciden con la idea de que cualquier narrativa histórica contiene elementos relacionados con la interpretación. Los dos puntos de vista mencionados, con respecto al Grito de Lares, ejemplificaron cómo la información sobre datos históricos está definida por la visión de quien la escribe "a clear and precise perception of a given domain of historical happening might look like differs from historian to historian" (White, 1978: 63). Sin embargo, hay constantes en el relato de la historia que sugieren cierta objetividad con respecto a algún acontecimiento específico. Para Puerto Rico, las historias narradas coinciden tanto en la fecha de la entrada de Estados Unidos a la isla, como en el hecho de que los puertorriqueños no opusieron resistencia a la invasión estadounidense. José Luis González escribe en su ensayo El país de cuatro pisos que tanto la clase propietaria como la clase trabajadora de la isla acogió la llegada de los estadounidenses. Los primeros porque pensaron que significaría el ingreso de Puerto Rico a la democracia, a la libertad y al progreso; los segundos por entenderla como la posibilidad de liberación con respecto a la clase propietaria (29-32). Por otro lado, Antonio Quiñones expone un dato interesante: incluso los separatistas puertorriqueños que se agruparon desde 1895 
en la sección de Puerto Rico del Partido Revolucionario Cubano — radicado en Estados Unidos - escribieron un manifiesto para que las tropas estadounidenses lo distribuyeran en la isla a su llegada. En éste expresaban que los estadounidenses ayudarían al pueblo de Puerto Rico a emanciparse y a alcanzar su plena ciudadanía, por lo tanto, invitaban a sus compatriotas a acoger a los recién llegados (65-66).

Si bien los diferentes grupos en la isla tenían distintas expectativas de la presencia estadounidense - cada uno de acuerdo con sus necesidades - , lo que parece un hecho es que el general Nelson A. Miles y sus tropas no se enfrentaron a una resistencia importante por parte del pueblo de Puerto Rico.

Ahora bien, las expectativas de salvación, liberadoras o de emancipación, no se cumplieron, muy por el contrario, la isla pasó de ser una colonia española al sometimiento a un nuevo orden. El 18 de octubre de 1898 inicia la soberanía de Estados Unidos sobre Puerto Rico mediante un régimen militar. Tras cinco décadas de dominación estadounidense, a pesar del ímpetu de muchos puertorriqueños por luchar bajo la insignia de un principio libertador — como el caso de Pedro Albizu Campos - , se prepara el escenario con el gobierno de Luis Muñoz Marín, ${ }^{5}$ quien induce a Puerto Rico a obtener la condición de Estado Libre Asociado en 1952. Desde su fundación, la isla sigue siendo un territorio no incorporado de Estados Unidos con estatus de autogobierno. A pesar de que, con base en los plebiscitos, la mayoría de los puertorriqueños parecen desear mantener la isla en esta situación política, existen evidencias de otras voces que, como escribe Manuel Maldonado Denis, resisten al colonialismo porque: "Los principios de valor universal no pueden ser aniquilados... todos los pueblos del mundo tienen derecho a ser libres" (198).

La historia tan peculiar de esta isla caribeña ha desembocado en reflexiones en torno al perfil del puertorriqueño. Existe una definición, no muy acogida por los habitantes de la isla, que los expone como individuos dóciles. Antonio Pedreira (Insularismo, 1934) introduce esta idea que más tarde, hacia 1960, es retomada y reescrita por René Marqués en El puertorriqueño dócil. Con la finalidad de dar prueba de la docilidad puertorriqueña, el autor comienza presentando una definición del término dócil: expone que el latín docilis significa "obedient" o "fulfilling the wishes of the one who commands" (35). Asimismo, presenta una definición tomada del Gran Diccionario de Sinónimos de Roque Bercia: "Docility is to lack the strength or even the will to put up resistance to what others demand, insinuate, or command; a propensity to obey, to follow the example..." (35).

\footnotetext{
${ }^{5}$ Cabe anotar que Luis Muñoz Marín es hijo de Luis Muñoz Rivera. Recuérdese que en Seva, López Nieves escribe sobre Luis M. Rivera como el traidor puertorriqueño que auxilia a las tropas estadounidenses. A pesar de que en la página 73 de la obra de López Nieves leemos que el profesor Adolfo Jiménez Hernández responde a ataques contra el autor de Seva por éste haber puesto en ridículo a Muñoz Rivera (Jiménez Hernández irónicamente señala que nunca se menciona a este político sino a un simple personaje Luis M. Rivera), es claro que López Nieves sí se refiere al padre de quien más tarde personificaría la esperanza de liberación puertorriqueña y, tristemente, continuaría la política colonialista que él practicó.
} 
Existe cierta coherencia entre la historia de Puerto Rico y la docilidad de sus habitantes propuesta por Pedreira y Marqués. El simple hecho de que por tantos siglos el pueblo haya estado sometido a un país más poderoso, refiere a la docilidad de dos maneras, como causa y/o como consecuencia de esta situación. Marqués se refiere también a otro término que ha sido utilizado para describir al puertorriqueño: aplatanado, explica con ironía que a este adjetivo se le ha impuesto un nuevo sinónimo: democrático, y esto ha promovido que el puertorriqueño acepte dócilmente y sin escrúpulos su condición abyecta (37). Bajo máscaras de democracia o por otras razones, lo que es incuestionable es la situación política que vive y que hace de Puerto Rico un caso único. Ante estas circunstancias, el puertorriqueño - independientemente de su opinión — ha sido definido como pacífico, tolerante, resignado, fatalista, aplatanado, ${ }^{6}$ apático. ${ }^{7}$ Para René Marqués el adjetivo que mejor engloba la descripción buscada es dócil, y expone pruebas que confirman su teoría, desde contenidos literarios de autores puertorriqueños, como la imposición en la isla de la lengua inglesa, el control estadounidense en el campo de la ciencia y otros indicios más.

Finalmente, Marqués expone la función que debe tener el escritor puertorriqueño tomando en cuenta el estado colonial de Puerto Rico: "Freedom is for the Puerto Rican writer the truth always sought and never captured" (118). El escritor debe de apuntar a la libertad como la última verdad. A pesar de que la situación política de la isla le impida alcanzarla, ésta debe ser la meta.

¿Cumple Luis López Nieves con la función del escritor puertorriqueño descrita por Marqués? El autor de Seva es empujado a la palabra a partir de lo que él es. López Nieves es puertorriqueño, como aquel que en 1508 fue colonizado por los españoles, como el que en 1898 vivió la invasión estadounidense y como el que ha sido descrito por Pedreira y por Marqués. A partir de su historia y de su nacionalidad puertorriqueña, López Nieves escribe y se reconoce libre en su papel de autor, cumple con esa cualidad que René Marqués exige en el escritor de Puerto Rico como colonia. Paradójicamente, expresando su libertad, López Nieves escribe Seva y presenta a un puertorriqueño que rompe con la imagen dócil.

En 1983 se publica Seva en el suplemento En Rojo del periódico Claridad. Por petición del autor, no se advierte al público que la historia que ahí se relata es un cuento. El texto comienza con una carta dirigida al director del periódico, en la que Luis López Nieves explica que lo que presentará es el resultado de una investigación que llevó a cabo un amigo suyo, Víctor Cabañas, quien ahora está desaparecido. La historia entonces se relata mediante las cartas que Víctor le ha enviado a Luis, páginas del diario del general Miles y, además, la información narrada se constata con otras modalidades discursivas

\footnotetext{
${ }^{6}$ Estos cinco adjetivos los menciona René Marqués como formas que han sido comúnmente utilizadas para describir al puertorriqueño (37)

${ }^{7}$ Más atrás, cuando se presentaron las visiones en torno al Grito de Lares, una de éstas, la que presenta la historiadora Carmen Ramos de Santiago, es la que explica el fracaso de este movimiento revolucionario por la apatía del puertorriqueño.
} 
como mapas, documentos oficiales, fotos y la mención de una grabación del único sobreviviente de Seva, Ignacio Martínez, quien sugerentemente es un cimarrón.

A través de estos medios, el lector se enfrenta a la lectura de una historia que supuestamente sucedió poco más de dos meses antes de la fecha pública en la que las tropas estadounidenses al mando del general Miles entran a la isla de Puerto Rico.

La sospecha del personaje Víctor Cabañas sobre la existencia de un fragmento de la historia escondido, comienza con un dato que encuentra en una copla de El cantar folklórico de Puerto Rico, del conocido autor Marcelino Canino, en la que dice que "los americanos llegaron en mayo", a partir de este indicio, Cabañas se somete a la más rigurosa investigación a través de la cual va recabando información que muestra que el 5 de mayo — no el 25 de julio como se pensaba hasta ese momento- de 1898, se llevó a cabo la primera invasión estadounidense y la entrada de las tropas tiene lugar por la playa del pueblo Seva - ya que la entrada por Guánica será la segunda, la difundida. A diferencia de lo que se le había hecho creer a la gente, a través de las cartas de Cabañas y del diario del general Miles que el propio Cabañas logra tomar del archivo de la nieta de Miles, el lector descubre que los puertorriqueños sí opusieron resistencia y defendieron su territorio. Asimismo, leemos que con gran heroísmo el pueblo puertorriqueño logró reducir las tropas estadounidenses en poco tiempo y llevó al enemigo a refugiarse en sus trincheras para sobrevivir a su asombrosa puntería.

Ante esta penosa entrada a territorio puertorriqueño, el general Miles se encarga junto con su equipo, con tropas nuevas y con la ayuda de un puertorriqueño que traiciona a su pueblo, Luis M. Rivera, de hacer desaparecer todo rastro de la oposición. Construyen una base militar sobre los escombros de Seva y construyen otro pueblo en las cercanías con un nombre parecido, Ceiba, para que poco a poco se vaya borrando de la memoria este fragmento tan desafortunado de la historia.

A través de esta obra, Luis López Nieves revive un nacionalismo reconstruyendo un pasado que responde a una necesidad personal. Esta necesidad, por estar ligada a su nacionalidad puertorriqueña, es compartida — desde un sentimiento profundo común - con el pueblo de Puerto Rico.

La reacción ante la publicación de Seva en el periódico Claridad fue tan fuerte que se incluye en la edición de Seva una crónica de Josean Ramos que la expone. Los puertorriqueños reaccionaron con "Una mezcla angustiosa de alegría, ira y dolor"; alegría por despojarse finalmente de la etiqueta del puertorriqueño dócil, ira por la brutalidad estadounidense ante el pueblo heroico de Seva y tristeza por haber perdido rastro de este espacio en el que se había llevado a cabo la valiente resistencia (62). Seva, al fin, reconstruía un pasado nacional que los podía hacer sentir orgullo. Movidos por este sentimiento patriótico, el pueblo reaccionó activamente. Hubo quienes querían buscar a Ignacio Martínez, otros pensaban en la importancia de encontrar los restos de Seva que yacían bajo la base naval de Roosevelt Roads. Se expresó la reacción en graffiti por las calles y se clavó una cruz con la insignia "Seva Vive", frente a la base naval estadounidense. La necesidad de creer, o el gusto que este pasado heroico generó, 
llevó a algunos lectores a negar el carácter ficticio del relato expuesto por el director de Claridad días después de la publicación de Seva.

Ramos presenta también una serie de opiniones de artistas e intelectuales ante la impactante respuesta a este relato, si bien se exponen puntos de vista encontrados, en resumen puede decirse que el relato de López Nieves despertó un nacionalismo que había permanecido callado.

\section{Nostalgia y remedio}

Como se expuso en la introducción, el propio autor reconoce como motor de su escritura a la nostalgia: "echaba de menos una epopeya puertorriqueña" (López Nieves: 85). En The Future of Nostalgia, Svetlana Boym define la nostalgia como: "(from nostos - return home, and algia - longin) is a longing for a home that no longer exists or has never existed. Nostalgia is a sentiment of loss and displacement, but it is also a romance with one's own fantasy" (XIII). Como el propio autor de Seva escribe, "ya que no existía (o no se conocía) una gloriosa y potente epopeya que "me emocionara y llenara de orgullo', sólo quedaba una cosa por hacer: inventarla” (85). Llevado por un sentimiento nostálgico, el autor hurga entre las posibilidades literarias y vuelve al pasado para fabricar el remedio.

Según señala Boym, el doctor suizo Johannes Hofer fue el primero en hablar de nostalgia en el año de 1688. Se relacionaba a este mal con la añoranza de la tierra nativa y, aunque podía ser un mal mortal, comúnmente podía controlarse con emulsiones cálidas hipnóticas, opio y quizás un viaje a los Alpes (3-4). Ciertamente, el concepto moderno de nostalgia es muy diferente. En el caso que ahora se estudia, la obra misma es el remedio, la escritura se convierte entonces en un acto de curación, ${ }^{8}$ nombrar es un acto de conjuro. De acuerdo con Boym, a finales del siglo XIX este sentimiento adquiere un estilo y espacios públicos (15). En el caso de Seva, la literatura funciona como un medio capaz de publicar un producto de la nostalgia, y este carácter público fue significativo ya que, mediante su lectura, Seva evidenció que la nostalgia del autor era común a su pueblo, y por lo tanto, lo que funcionaba como remedio a su nostalgia, es decir, la escritura de esta epopeya, se convirtió - aunque evidentemente de distinta manera, el autor escribe una historia ficticia y el lector cree en lo narrado- en un remedio temporal colectivo. Temporal porque el carácter ficticio fue develado.

Boym propone dos tipos de nostalgia que tienen que ver con la manera en la que el ser humano se relaciona con el pasado (41):

1. Nostalgia restaurativa: el individuo se enfoca principalmente en el hogar perdido y desea reconstruirlo para llenar los vacíos en la memoria.

\footnotetext{
${ }^{8}$ Más adelante se propondrá que al ser una ficción el remedio a la nostalgia no puede ser permanente, por lo tanto vale la pena matizar el término curación.
} 
2. Nostalgia reflexiva: el individuo se sumerge en la añoranza. Se rezaga en las ruinas y pátina de la historia y sueña con un mundo que ya no existe.

Podrían interpretarse estas dos tendencias de la nostalgia que propone la autora rusa como las dos maneras en las que el individuo puede o quiere enfrentarse a lo que le ocasiona el sentimiento nostálgico, ya sea de forma activa o restaurativa, o de manera pasiva o reflexiva.

En el caso de Luis López Nieves y su escritura de Seva, el tipo de nostalgia que expresa responde a la de tipo restaurativa. El autor convierte en reversible el carácter irreversible de la historia, así como el del tatuaje de docilidad que parecía imborrable en la piel puertorriqueña. De acuerdo con Boym, la nostalgia restaurativa se enfoca principalmente en dos síntomas, el dolor por la distancia temporal y el desplazamiento (44). Con la escritura de Seva, López Nieves rompe con la distancia temporal de la historia, irrumpe en ella y hace los cambios necesarios que le permitan recobrar el lugar perdido por el desplazamiento que el puertorriqueño ha sufrido en su propia tierra. Al hacerlo, revive un nacionalismo — en los primeros lectores 9 — que permanecía quieto, y esto debido quizás a que el motivo de la nostalgia es escurridizo, "The alluring object of nostalgia is notoriously elusive" (Boym, 2001: XIV). La respuesta ferviente que tuvo la lectura de Seva fue la evidencia de que una añoranza callada yacía inmóvil en lo más profundo del pueblo de Puerto Rico.

Mediante distintos modos de significar, López Nieves construye al héroe puertorriqueño que contradice la imagen que por tantos años se le ha atribuido al nativo de Puerto Rico. Contrapunteando con el perfil dócil delineado por Marqués, en Seva se dibuja al héroe, y lo que es mejor, la descripción la hace el enemigo apabullado. Leemos en el diario del general Miles: "iniciamos la marcha triunfal hacia el pueblo y fue entonces que nos sorprendió una formidable fuerza enemiga" (26), y más adelante escribe: "Es imposible alcanzar al enemigo. Estamos totalmente atrapados, impotentes por completo" (27). El autor de Seva da remedio a su nostalgia escribiendo la epopeya que su pueblo necesita y cumpliendo con el sueño de invertir los papeles y dominar -ficticiamente - a los opresores: "Es asombrosa la puntería de estos hijos de puta... Mis soldados viven como ratones atrincherados" (28). Después de haber exterminado al pueblo de Seva, el general Miles describe en su diario la resistencia por parte de los puertorriqueños: "Debo admitir que opusieron una resistencia feroz, organizada y heroica, digna de nuestra independencia contra los británicos y a la altura de un Cid o un Wellington. Ni siquiera en Wounded Knee vi yo tantos actos heroicos como he visto en Seva" (34). Aquí se confirma la epopeya que López Nieves extrañaba y al no tenerla la inventa. El puertorriqueño inventado no solamente opuso resistencia al enemigo sino que su labor estuvo a la altura de los grandes héroes.

\footnotetext{
${ }^{9}$ Subrayo que en este ensayo únicamente me referiré a los lectores de la primera publicación de Seva, la que aparece en el periódico Claridad.
} 
Ahora bien, en cuanto a la respuesta del público ante la publicación de Seva en Claridad, se evidencia, como se ha mencionado, una nostalgia compartida por autor y lector a causa de la historia que les es común. Parece que en el acto de la lectura se detona un ímpetu por restaurar el pasado, que finalmente no es otra cosa que el comienzo de la situación actual en la isla. Sin embargo, la forma discursiva que López Nieves utiliza, así como los distintos medios de representación, confieren a Seva un tono verídico que promueve el efecto logrado.

\section{Seva o Ceiba: el engaño}

[...] el árbol que está allá entre los árboles no es el árbol que digo sino una realidad que está más allá de los nombres, más allá de la palabra realidad, es la realidad tal cual...

Octavio Paz, El mono gramático (49)

Una de las particularidades de la palabra es que permite referirnos a las cosas sin tener que percibirlas, detrás de ésta, el universo referencial permanece callado y oculto. $\mathrm{Al}$ respecto, Heidegger escribe que al nombrar se rodea a los objetos con palabras y al mismo tiempo se llama a las cosas, "El nombrar invoca" (19) pero explica, "La invocación invoca en sí y, por ello, llama hacia aquí, hacia la presencia y llama hacia allá, en la ausencia" (19). Es decir, que por medio de la palabra se detona la presencia del referente aludido y al mismo tiempo se hace explícito el hecho de no mostrarlo. El filósofo alemán se pregunta entonces cuál es la presencia más fuerte, la que está ante nuestros ojos o la invocada. Difícilmente podemos responder a esta pregunta. Lo que es un hecho es que cada forma de representación tiene particularidades que determinan sus posibilidades ante lo que se busque expresar.

En Seva, el autor utiliza distintos modos discursivos que promueven la ilusión de que la historia y los datos representados son verídicos. Ante el cuestionamiento de Heidegger, en este relato nos enfrentamos a las dos maneras de significación, aquellas que muestran referentes específicos como las fotografías y las que se configuran mediante signos lingüísticos como las cartas y el diario del general Miles, entre otras.

Evidentemente, como obra literaria, el medio de representación principal es el de la palabra y López Nieves lo utiliza de tal manera que, al igual que los documentos anexados, generan la ilusión de verdad. La palabra permite referirse a las cosas sin la necesidad de mostrarlas; esto potencializa las posibilidades del medio porque el escritor no se ve limitado ante el mundo referencial que le rodea, y por lo tanto, su punto de partida es infinito. De este universo infinito de posibilidades referenciales, López Nieves elige un evento en la historia de Puerto Rico. Con esta demarcación espacial comienza a generarse lo que Luz Aurora Pimentel denomina ilusión referencial o iconización, "cuando hablamos del espacio en el relato, nos referimos más bien a la ilusión del espacio que se produce en el lector gracias a una serie de recursos descrip- 
tivos altamente codificados" (27). Si bien la palabra significa sin imitar, a partir de lo que Pimentel señala, puede verse que existen mecanismos de la lengua que permiten generar la ilusión mostrativa que tienen otros medios de representación y que acercan lo narrado a un plano tangible, y por lo tanto, más próximo. Esta proximidad, en el caso de Seva, ayuda a simular que lo narrado realmente ocurrió.

Pimentel propone que la visualización mental del mundo puede ser promovida mediante los siguientes elementos (35-37):

—Lexemas con propiedades semánticas estables.

- Iconización de objetos, sujetos y lugares particularizados.

-Nombres propios que sean semánticamente estables y promuevan determinadas mitologías.

En Seva encontramos los tres elementos. El uso de lexemas con propiedades semánticas estables es muy evidente y no requiere mayor explicación. Lo que leemos responde a un código convencional y por lo tanto es comprensible e imaginable, es decir, que los lexemas con significados referenciales generan la imagen mental de lo que representan, de este modo contribuyen a la configuración de un momento y de un espacio específicos. De acuerdo con Pimentel, la iconización de objetos, sujetos y lugares se da mediante el uso de adjetivos y toda clase de frases que califiquen la configuración del personaje. En Seva, la configuración y la particularización de Víctor Cabañas es primordial. En este personaje recae la veracidad del contenido narrado y además constituye el elemento de tensión que se mantiene a lo largo del relato. Desde la carta que abre con el cuento en la cual Luis López Nieves se dirige al director del periódico Claridad, el autor, López Nieves, informa que la documentación que entrega para su publicación es producto de la investigación que llevó a cabo su buen amigo Víctor Cabañas "(quien fuera hasta hace poco tiempo, antes de desaparecer, profesor de Historia de la Universidad Interamericana de Puerto Rico)" (16). Sabemos entonces que quien recabó la información que leeremos está desaparecido. López Nieves particulariza a su personaje como un académico, de este modo se avala la seriedad de la labor de investigación que se expondrá. El hecho de que intercale elementos ficticios -el personaje Víctor Cabañas - con referentes existentes - Universidad Interamericana de Puerto Rico - promueve la ubicación del elemento inventado dentro de un mundo referencial conocido. Este mecanismo lo encontraremos a lo largo de toda la obra. La situación crítica de Víctor Cabañas es reforzada desde las primeras líneas de su diario en las cuales - a manera epistolar — se dirige a su amigo Luis, "ya intuyo que algo anda terriblemente mal. En términos generales, creo que sé cuidarme y que nada me ocurrirá. Pero de no ser así estarás tú para saber que hacer y cómo ayudarme" (18). Se iconiza a Cabañas particularizándolo como un personaje políticamente vulnerable por su investigación en torno a la historia escondida de Puerto Rico.

El dato que detona en Víctor Cabañas la sospecha sobre la verdadera entrada de las tropas estadounidenses a Puerto Rico es otro ejemplo claro de particularización 
en la que, además, el entrelazamiento de un objeto existente con información falsa permite y ayuda a la intención de hacer pasar lo inventado como verdadero. Se trata de la copla —inexistente - "los americanos llegaron en mayo" que Cabañas encuentra en la página 135 de El cantar folklórico de Puerto Rico bajo la autoría del Dr. Marcelino Canino (18-19). La especificidad del dato — página 135- y la existencia del autor - Canino-, así como del libro mencionado, lleva al lector a tomar como verdadero el descubrimiento de la mencionada copla.

Los ejemplos de particularización en Seva son muchos, basta ahora con mencionar uno más que resulta primordial en el relato de este cuento. Se trata de la presencia - como objeto - del diario del general Nelson Miles. Cabañas le cuenta a Luis, en su diario con forma epistolar, que durante la visita a la nieta de Miles encuentra el diario del general Nelson Miles. Le cuenta que lo traduce lo más fielmente posible; sin embargo, a pesar de que narra el contenido traducido, conserva el modo y uso de lenguaje íntimo que caracteriza a un diario, de este modo López Nieves logra particularizar el objeto como tal con su valor documental. El recurso que enfatiza la particularización y por lo tanto la ilusión referencial es el anexo de lo que supuestamente es una página del diario del general Miles. Al presentar una muestra del supuesto diario original, escrito en inglés, con letra manuscrita, e incluso la presencia de un tachón, López Nieves logra enfatizar el carácter no ficticio de lo que en realidad es un artificio literario.

El último de los recursos que Pimentel propone para generar la ilusión referencial es el uso de nombres propios que son semánticamente estables, y por lo tanto, promueven determinadas mitologías. Éste es un recurso muy utilizado en Seva, López Nieves entrelaza datos ficticios con otros verdaderos y de esta forma empuja su invención al terreno de la verdad. Entre los nombres que implican un cúmulo referencial específico encontramos en primer lugar a la isla de Puerto Rico en el momento histórico narrado, es decir, a la llegada de las tropas estadounidenses. Aunque esto parezca obvio, es el ejemplo básico de nombre propio estable en este relato y lo interesante es que el autor modificará la estabilidad de éste al descubrir ante el público un pueblo desconocido - Seva - como parte integral de la isla. En la primera línea tomada del diario del general Miles leemos: "Hoy comenzó la invasión de Porto Rico... desembarcamos a 1000 horas por la playa del pueblo de Seva" (26), el simple hecho de nombrar a Porto Rico invoca a esta isla y la narración ubica al país en un momento determinado. Una vez más, la presencia de un espacio ficticio - Seva — entra al terreno real de los referentes existentes que lo acompañan.

Además de Puerto Rico, otros nombres que invocan un universo referencial específico son: el Dr. Marcelino Canino, poeta, narrador y ensayista puertorriqueño. General Nelson Miles, comandante general de Estados Unidos desde 1895 y durante la Guerra hispanoamericana, asimismo, caudillo de la invasión puertorriqueña. Luis M. Rivera, secretario de Gracia y Justicia y de Gobernación durante el breve régimen autónomo, fundador del Partido Liberal y el Partido Unión de Puerto Rico, más tarde, comisionado residente en Washington. A pesar de que en el diario del general Miles se omite el primer apellido el lector deduce que se trata de Luis Muñoz Rivera, incluso 
el mismo Cabañas le escribe a Luis "no es difícil adivinar quién es Luis M. Rivera ya que los norteamericanos nunca han podido entender que nuestro segundo apellido es materno" (40).

Otros nombres que contribuyen a la ilusión referencial o iconización en Seva son: la Base Naval Roosevelt Roads, base aérea militar estadounidense que tiene su base en Ceiba. El Barrio El Duque en Naguabo, Naguabo es uno de los setenta y ocho municipios de Puerto Rico y El Duque es uno de los nueve barrios ubicado en este municipio. Es en este barrio en donde según Cabañas se encuentra con el único sobreviviente de Seva, Ignacio Martínez.

De acuerdo con estos ejemplos de nombres que invocan un mundo referencial, puede verse que aunque algunos no tengan un carácter local, otros sí son muy específicos, por ejemplo el Barrio El Duque, este último cumplirá puntualmente con su función de generar una ilusión referencial en los habitantes de la isla que están familiarizados con estos espacios. Sin embargo, para lectores que no compartan esta información, la especificidad en los datos, aunque no refiera a referentes conocidos, promueve la ilusión de verdad.

A pesar del carácter no mostrativo de la palabra, el autor literario puede generar una ilusión referencial que, si bien facilita y particulariza la forma en la que el lector actualiza mentalmente el texto, también —y esto es lo que se quiere subrayar aquígenera un efecto de verosimilitud en lo leído.

Ahora bien, existen otros recursos discursivos que López Nieves utiliza y que apoyan el carácter documental, y por lo tanto verídico, que Seva parece tener. Ya se mencionó cómo la particularización del diario del general Miles es un factor que genera una ilusión referencial. Asimismo, leemos que Cabañas llama diario a sus apuntes que dan cuenta de sus avances en la investigación; sin embargo, este diario se conforma por cartas dirigidas a su amigo Luis. Con respecto a esta forma, la epistolar, ya desde la Edad Media en los ars dictaminis se enfatizaba el hecho de que a diferencia de otras formas discursivas en las que el autor o el orador estaba presente, en el caso de la lectura de una carta se evidenciaba la ausencia del que la había escrito. Con respecto a esto, Alberic of Montecassino escribe: "Next the writer should ask himself what attitude he wishes to project: proud or humble, harsh or forgiving, threatening, flattering, stern, or that of a trusted friend" (138). En este sentido, podría pensarse que la carta debe de tener los elementos necesarios que puedan sustituir a la persona que la escribe. En Seneca's Letters to Lucilius encontramos esta idea de forma muy clara:

Thank you for writing so often. You give me a glimpse of yourself in the only way you can. I never get a letter from you without instantly feeling we're together. If there's a satisfaction in pictures of absent friends, which refresh a memory and relieve a void by a fictious and unsubstantial solace, how much more is there in letters, which bring us the genuine stamp, the authentic sign-manual of a friend far away. For the impress of our friend's hand on a letter affords that sense of his personality which is your keenest pleasure in seeing him ("Seneca, 1932: 123"). 
El concepto de Séneca sobre el poder de una carta resulta muy interesante para el estudio de esta modalidad discursiva en Seva, ya que el diario de Víctor Cabañas dirigido a Luis se constituye por cartas. De acuerdo con las ideas planteadas en torno a la ilusión referencial y en relación con la cita de Séneca, puede afirmarse que las cartas de Cabañas lo representan metonímicamente. ${ }^{10} \mathrm{~A}$ través de éstas, podemos leer a un Cabañas presente a lo largo del cuento, en sus palabras aparece él mismo proyectado como sugiere Montecassino, con el ímpetu por encontrar la verdadera historia de la invasión estadounidense y con el entusiasmo por los frutos de su investigación. A su vez, el empuje y emoción del personaje aparece turbado por la posible persecución ante su labor. De acuerdo con la cita de Séneca, puede entenderse este recurso literario como una forma de hacer presente al autor ficticio y de este modo insertarlo en un mundo real en el que su presencia es más poderosa de lo que podría llegar a ser un retrato del mismo. La inserción de una de las cartas escrita a mano - the authentic sign-manual of a friend far away - potencializa el poder del recurso; la presencia de su propia letra promueve la ilusión referencial y en este caso fomenta la credibilidad.

Según Séneca, la carta, en relación con el retrato de una persona, constituye una estampa más genuina. Sin embargo, existe una forma de retrato distinta a la que Séneca conoció, la fotografía. La presencia de este medio en Seva contribuye en buena medida al efecto de verdad que se le dio. Si bien está por demás explicar los avances tecnológicos que hacen que toda imagen fotográfica sea cuestionable, es curioso que la fotografía todavía parece tomarse como un medio que representa evidencias. La razón de esto no es otra que la naturaleza técnica del medio, así como el uso histórico que se le ha dado. Por mucho tiempo se ha entendido a esta forma de significación como aquella en la que lo fotografiado se representara por sí mismo, como si el proceso de representación respondiera a un automatismo en el cual los objetos se delinearan solos. Puede decirse que se le ha atribuido una objetividad intrínseca al medio. A diferencia de la palabra, mediante la cual se representa sin mostrar y, por lo tanto, permite que las cosas se escondan detrás de los renglones que llena, la fotografía - aunque pueda no reconocerse lo que aparece en una imagen - nos presenta un mundo referencial.

En Seva, López Nieves aprovecha el valor documental que aún se le da a la imagen fotográfica y esto es reforzado por el hecho de que presenta imágenes que refieren a un pasado - 1898 - en el que, a pesar de que ya se practicaban algunas formas de manipulación, la tecnología no ponía estas posibilidades en manos del público, como sucede en nuestros días. Ahora bien, se vale de esta forma de significación de distintas maneras. En primer lugar echa mano de un recurso que es utilizado por varios artistas desde los años sesentas, la apropiación. "Any image can be removed from its

\footnotetext{
${ }^{10}$ Una de las definiciones que Geoffrey of Vinsauff presenta en torno a la metonimia en su Poetria Nova se basa en una relación de instrumento por el que lo utiliza, "art teaches us to attribute to the instrument, by a happy turn of expression, what is proper to the one who uses it" (51). Con base en esta definición podemos afirmar que las cartas de Víctor Cabañas funcionan como una metonimia en las que, como instrumento, lo sustituyen. Cumplen una finalidad específica para él, que su investigación quede en manos de un amigo que pueda difundirla en caso de que él no lo pueda hacer.
} 
original context and put to a different use. This approach has come to be known as appropiation" (Mora, 1998: 49). En Seva, responden a este uso las imágenes del general Nelson Miles, la del acorazado Iowa, la fotografía de El Gloucester disparando a la entrada del puerto de Guánica y la que muestra — según lo que escribe el autor en una nota a pie de foto- a una partida de sediciosos capturada en Ponce a finales de 1898. Todas estas imágenes son ejemplo de lo que se conoce como fotografía documental, y por lo tanto son consideradas como una fuente fiable de información. El efecto de estos recursos en combinación con la ficción en Seva funciona, reforzando lo que ya se ha mencionado hasta ahora, como una manera de transferir la invención al mundo real que en este caso es mostrado — no sólo invocado, ${ }^{11}$ como lo hace la palabra- a través de imágenes. El valor de verdad que se le da a la fotografía funciona aquí como aval de la información que la acompaña, es decir, del relato.

La fotografía ausente de Ignacio Martínez, a pesar de no aparecer publicada, es sugerida con el espacio que se respeta para su posible inserción. El cuadro en blanco recuerda a las ideas del fotógrafo y teórico catalán Joan Fontcuberta, quien partiendo de la analogía entre espejos y fotografía que ha sido común desde los orígenes del medio, propone dos tipos de reflejo, el de Narciso y el del Vampiro, "narcisos y vampiros designarían también categorías contrapuestas en el mundo de la representación. En unos prevalece la seducción de lo real; en otros, la frustración del deseo, la presencia escondida, la desaparición" (41-41). Las fotografías que Luis López Nieves se apropia e inserta en su relato podrían ubicarse dentro de la categoría de Narciso, en la que la intención fotográfica es representar lo real, documentarlo. Se exalta la presencia en la imagen del general Miles y se busca documentar la llegada de las tropas en el acorazado. Por el contrario, la imagen del personaje ficticio, Ignacio Martínez, no se publica. Se supone que existe, pero "el único sobreviviente de Seva" prefiere conservar su anonimato. A pesar de que se presenta la explicación sobre la ausencia de la imagen, se respeta el espacio y se dibuja un marco en el lugar que debería aparecer la fotografía. Esto sugiere que la imagen está ahí, pero que se trata de una presencia escondida. La ausencia de imagen del cimarrón que se resiste ejemplifica literalmente la desaparición sobre la que escribe Fontcuberta.

Además de las formas de significación que se han analizado hasta ahora, López Nieves inserta, entre otras, un afidávit con la huella digital de Ignacio Martínez (porque no sabe firmar). Si bien el espacio en blanco reservado para la fotografía de este personaje dio cuenta de su presencia escondida, tenemos también una huella que lo representa. Dos indicios de su existencia promueven la creencia en él. Con el recurso de esta forma que se basa en la confianza pública se reitera la existencia de este sobreviviente, así como la veracidad de todos los hechos narrados. Un testigo y un notario lo firman y avalan.

Se incluyen también dos mapas de Puerto Rico, uno, de 1896, que encontró Víctor Cabañas en una biblioteca de una pequeña ciudad en Galicia; el otro es un mapa

\footnotetext{
${ }^{11}$ Invocado o generando una ilusión referencial.
} 
actual. Por el tamaño es imposible ver si el autor insertó el nombre de Seva, pero no es necesario; se señala con una flecha la ubicación de esta ciudad. En el mapa actual, marca la ubicación de la base naval Roosevelt Roads construida sobre los escombros de lo que fue Seva. Desde una perspectiva semiótica peirceana, ${ }^{12}$ los mapas ejemplifican a los legisignos icónicos. ${ }^{13}$ Lo que resulta relevante ahora es que este tipo de signos representan la semejanza - en este caso con respecto a la isla de Puerto Rico- de una manera convencional, es decir, con base en una ley compartida entre las personas que podrán comprender la manera en la que, éste, significa un espacio específico. Su representación se fundamenta en una relación entre los símbolos convencionales que lo constituyen para mostrar las relaciones en los terrenos reales referidos. El hecho de que López Nieves manipule un mapa existente o invente uno con el fin de insertar un pueblo — o dar la idea de que éste existe mediante el uso de una flecha sobre el mismo- implica corroborar su existencia mediante un medio de representación que existe y puede significar gracias a un código o ley compartido, y por lo tanto confiable.

Además de los mapas, López Nieves inserta una caricatura política y la Proclama del Cuartel General del Ejército de Estados Unidos. Un vez más, la presencia de documentos reales dialoga con los ficticios con una naturalidad que impulsa al lector a creer en lo narrado.

Por último, se menciona como parte de los anexos una grabación en la que se puede escuchar el testimonio de Ignacio Martínez. Además de los documentos estudiados, el autor expande el potencial del relato ficticio mediante pruebas que apuntan a un sentido distinto, al auditivo. López Nieves no deja hueco en su ficción. Las grabaciones del único sobreviviente, al no ser transcritas, prometen una dosis más — que queda pendiente - del remedio a la nostalgia.

A lo largo de este ensayo se expuso cómo el motivo que lleva a Luis López Nieves a la escritura de este cuento, es decir, la nostalgia, responde a una historia compartida por los puertorriqueños y, por esta razón, porque el autor de Seva escribe desde su nostalgia como puertorriqueño; su obra causa el efecto que tuvo y pone en evidencia el objeto de añoranza que quizás antes de la lectura permanecía callado. Si bien se propuso que la necesidad común — de autor y público — por voltear atrás y descubrir una historia que los enorgulleciera fue un factor importante para tomar por cierto el cuento de Seva, asimismo se quiso presentar un análisis de las distintas modalidades discursivas que también tuvieron que promover la repuesta de los lectores en el periódico Claridad.

\footnotetext{
${ }^{12}$ Me refiero aquí a Charles Sanders Peirce, el principal teórico de la semiótica de base lógicofilosófico anglosajona.

${ }^{13}$ El legisigno icónico, de acuerdo con la propuesta semiótica de Charles Sanders Peirce, es un signo que representa algo — que no está presente - con base en una ley. Es decir, que para que pueda ser comprendido es necesario conocer el código que utiliza para estar en lugar de otra cosa. El carácter icónico se desprende de la relación que guarda con respecto a lo representado. En el caso de un mapa, éste guarda relaciones de semejanza con respecto a dimensiones espaciales reales. Esta información puede encontrarse más detallada en La ciencia de la semiótica, de Charles Sanders Peirce.
} 
En su obra Del texto a la acción. Ensayos de hermenéutica II, Paul Ricoeur plantea algunas ideas en torno a la imaginación en el discurso y en la acción. Refiriéndose a la práctica, el autor escribe que a partir de la acción narrada en un texto literario, el lector proyecta su imaginación. De este modo, se procura una representación ficticia de él mismo. Expone que el ser humano está históricamente vinculado a los demás y a través de la imaginación puede transferir el yo. A este proceso lo llama analogía de acoplamiento, "cada uno de nosotros puede, en principio, ejercer como cualquier otro la función del yo e imputarse a sí mismo su propia experiencia" (209).

Al reconocerse caído como el ángel poeta de Milton, López Nieves busca un mundo idílico perdido e inventa Seva. El público, al leer el relato, cree en la existencia de ese mundo narrado. De este modo, ambos curan su nostalgia, y es que en cada héroe de Seva, en aquellos que sometieron a los opresores, se reflejaban ellos mismos. Como propone Ricoeur, cada uno de nosotros puede, la fuerza y nacionalismo de los habitantes de Seva que opusieron resistencia es ahora la fuerza y nacionalismo de los lectores. Escribe José Manuel Torres Santiago: "Seva es la verdad de lo que somos: la verdadera historia del heroísmo puertorriqueño" (López Nieves, 2003: 79).

Ciertamente la respuesta del público ante la historia reconstruida evidenció una empatía en el pueblo puertorriqueño que denota una inconformidad ante la situación política de la isla. Seva constituyó la posibilidad de reconstruir una identidad nacional volviendo la vista al pasado. Si esto no fue posible, si Seva sólo sirvió como remedio temporal a la nostalgia, es necesario — como señala José Luis González - reconstruir hacia adelante, apuntar hacia el futuro. Solamente de esta manera se podrá rescatar, fuera de la ficción, la caribeñidad de la isla.

\section{Obras citadas}

BoYM, Svetlana. 2001. The Future of Nostalgia. Nueva York: Basic Books.

FonTCUBERTA, Joan. 1997. "Elogio del vampiro". Fotografia y verdad. Barcelona: Gustavo Gili. Pp. 33-51.

GonZÁlEZ, José Luis. 1982. "El país de cuatro pisos". El país de cuatro pisos y otros ensayos. Puerto Rico: Huracán. Pp. 11-43.

HeIDEGger, Martin. 1987. "El habla”. De camino al habla. Barcelona: Serbal. Pp. 11-31.

LÓPEZ NiEVES, Luis. 2003. Seva. Historia de la primera invasión norteamericana de la isla de Puerto Rico ocurrida en mayo de 1898. Puerto Rico: Cordillera.

Maldonado, Denis. 1969. Puerto Rico. Una interpretación histórico-social. México: Siglo XXI Editores.

MARQuÉS, René. 1976. The Docile Puerto Rican. Filadelfia: Temple University Press. MONTE CASsINO, Alberic. 1973. "Flowers of Rhetoric". Readings in Medieval Rhetoric. Ed. Joseph M. Miller, Michael H. Prosser y Thomas W. BenSON. Bloomington: Indiana University Press. Pp. 131-161. 
Mora, Gilles. 1998. Photo Speak. Nueva York: Abbeville Press.

PAZ, Octavio. 1998. El mono gramático. Barcelona: Galaxia Gutemberg.

PIMENTELL, Luz Aurora. 1998. "Mundo narrado I. La dimensión espacial del relato". Relato en perspectiva. Estudio de teoría narrativa. México: Siglo XXI Editores. Pp. 25-41.

QuiÑones CAlderón, Antonio. 2002. Historia política de Puerto Rico, vol. I. San Sebastián: The Credibility Group.

Ricoeur, Paul. 2004. "La imaginación en el discurso y en la acción". Del texto a la acción. Ensayos de hermenéutica II. México: FCE. Pp. 197-218.

SÉNECA. 1932. Seneca's Letters to Lucilius, vol. I. Oxford: Clarendon Press.

VINSAUF, Geoffrey of. 1967. "Ornaments of Style”. Poetria Nova. Toronto: Pontifical Institute of Medieval Studies. Pp. 42-86.

WHITE, Hayden. 1978. "Interpretation in History". Tropics of Discourse. Baltimore: Johns Hopkins University Press. Pp. 51-80. 